\title{
Genetic Characterization by SSR Markers of a Comprehensive Wine Grape Collection Conserved at Rancho de la Merced (Andalusia, Spain)
}

Enrico Cretazzo ( $\nabla$ enrico.cretazzo@juntadeandalucia.es )

Instituto de Investigación y Formación Agraria y Pesquera (IFAPA), Centro Rancho de la Merced

Paula Moreno Sanz

University of Trento

Silvia Lorenzi

Fondazione Edmund Mach (FEM)

Miguel Lara Benítez

Instituto de Investigación y Formación Agraria y Pesquera (IFAPA), Centro Rancho de la Merced

Leonardo Velasco

Instituto de Investigación y Formación Agraria y Pesquera (IFAPA), Centro de Málaga

Francesco Emanuelli

Fondazione Edmund Mach (FEM)

\section{Research Article}

Keywords: microsatellites, grapevine germplasm, genetic diversity, eco-geographic differentiation, core collection

Posted Date: February 16th, 2022

DOI: https://doi.org/10.21203/rs.3.rs-1268246/v1

License: (c) (1) This work is licensed under a Creative Commons Attribution 4.0 International License. Read Full License

Version of Record: A version of this preprint was published at Plants on April 16th, 2022. See the published version at https://doi.org/10.3390/plants11081088. 


\section{Abstract}

Background: The IFAPA research center "Rancho de la Merced" (Jerez, Spain), hosts one of the oldest and widest grapevine germplasm banks in Europe, and is aimed at providing feasible solutions to deal with any agronomic trait by exploring its genetic variability and by means of association and DNA editing studies. In this work we focused on a wine and dual-use grapevine sub-collection that consists of 930 accessions.

Results: Genetic analysis allowed to identify 521 unique genotypes. After comparing them with several databases, matches were found for 480 genetic profiles while the remaining 45 have not been previously described. Combination with clustering analysis suggested a total pool of 481 Vitis vinifera accessions that included some table cultivars. Several synonymies, homonymies and mislabeling have also been detected. Structure analysis allowed identifying six clusters according to eco-geographic cultivation areas and one additional group including non-vinifera accessions. Diversity analysis pointed out that Spanish Mediterranean varieties are genetically closer to oriental genotypes than to European varieties typical of oceanic and continental climates. The origin of Spanish varieties is discussed in depth considering our data and previous studies.

Conclusions: Analysis of molecular variance partition confirmed a well-structured germplasm, although differentiation among groups had a much lower effect on genetic variability than differences within groups, which are strongly related to a very high heterozygosity. A core collection that covers all allele richness is proposed. It is constituted by about $13 \%$ of total accessions, and each cluster inferred by structure analysis is represented.

\section{Background}

Germplasm banks are a strategic resource for plant biodiversity conservation. Their efficient management and use are critical issues, especially in the case of field genebanks which maintenance can be really expensive. Well-managed plant collections both safeguard genetic diversity and make it available to breeders [1]. Grapevine (Vitis spp.) is a major vegetative propagated fruit crop with high socioeconomic importance worldwide [2] owning a millenary history with lots of natural and human-mediated crossings and dispersions, originating thousands of varieties within the most economically important specie in the genus, Vitis vinifera L. [3]. For these reasons, grapevine genebanks have been established all around the world. The Vitis International Variety Catalogue (VIVC, https://www.vivc.de/index.php?r=cultivarname\%2Findex, [4]) provides a comprehensive summary of worldwide grapevine collections, making available a database with around 23000 cultivars, breeding lines and Vitis species. For each accession, VIVC attempts to compile information about denominations (prime name and synonymies), historic references, passport data, morphological traits, use, molecular markers for identification, pedigree etc. "Microsatellites by varieties" and "microsatellites by profiles" are especially useful sections, which support cultivar identification by providing genetic profiles of the nine Genres081/GrapeGen06 SSR markers VVS2, VVMD5, VVMD7, VVMD25, VVMD27, VVMD28, VVMD32, VrZAG62 and VrZAG79 [5] for more than 2000 cultivars. Nuclear microsatellite markers (SSRs), due to their polymorphism, reproducibility, hypervariability and codominant nature, are an efficient tool to manage germplasm collections [6] and have been increasingly used as molecular descriptors in grape, which allow compilation, standardization and exchange of information concerning grapevine genetic resources [7]. The genetic structure, genetic diversity and cultivar parentage relationships have been inferred by SSRs in some of the widest grape genebanks, as The INRA "Domaine de Vassal” Grape Germplasm Repository (France, [8,9]) and the FEM grape germplasm collection at San Michele all'Adige (Italy, [10]). SSRs can also be successfully used, alone or in combination with other genetic or phenotypic markers, to extract subsamples known as core collections that capture, with minimum redundancy, most of the available genetic diversity of a crop, a wild species or a group of species, allowing a more effective management, research and utilization of the existing variation in a large collection [11]. Core collections have been inferred from grapevine genebanks in order to manage a reasonable number of individuals to approach breeding programs [10,12,13,14]. Besides nuclear SSRs, chloroplast SSRs can help to disclose the geographic distribution of grapevine varieties and elucidate the relationships between sylvestris and sativa grapevine groups [15]. In grapevine, chloroplast SSRs are maternally inherited and generate a reduced number of specific chlorotypes that can be related to a geographic origin. The VIVC recognizes this information for a consistent number of grapevine varieties and other accessions. In this paper, 930 Vitis accessions belonging to the "Rancho de la Merced" grape germplasm collection (IFAPA, Jerez de la Frontera, Andalusia, Spain) have been studied by 13 nuclear microsatellites. It is the most ancient and the second biggest grape genebank in Spain and one of the most important worldwide with approximately 1,800 accessions among sativa and sy/vestris grapevines, Vitis species, rootstocks and interspecific crossings. Its origin dates back to the foundation of the "Granja Escuela Práctica de Agricultura Regional de Jerez de la Frontera" in 1887, as a response to phylloxera appearance in southern Spain. In order to assess the local vitiviniculture facing this major concern, in 1907 the first Spanish ampelographic station was established in Jerez and included a collection of rootstocks and grapevine cultivars [16]. The germplasm collection was established at "Rancho de la Merced" property in 1940, and between 1984 and 1987 was replanted and the number of accessions substantially increased. To date, only phenological and must quality evaluations of several accessions are available [16]. A new replantation is now required due to the declined vineyard status. Therefore, the genotypic characterization by genetic markers is essential for a correct identification, which represents the first step in germplasm management [17]. Due to limited resources and practicality, replantation of the entire collection will not be done all at once, but by batches. The 930 studied accessions are planted in three plots assigned to conservation of wine grapevine varieties for which replantation will be firstly achieved, since wine is largely the prevalent use for cultivated grapevine in both Spain and Andalusia ( $98 \%$ and $88 \%$, respectively, [18]). The rest of the genebank is currently under genotypic identification. The 930 SSR profiles obtained have allowed detecting synonymies, mislabeling, redundancies and somatic mutants and will help to optimize the collection management. Genetic structure and diversity have been inferred, results have been integrated with information provided by the VIVC and compared with other related studies in order to discuss the origin of Spanish grapevine varieties. Provided that southern Spain viticulture is being especially concerned by main issues as climate change [19] and trunk diseases [20], two core collections based on SSR markers have been pointed out for further breeding programs.

\section{Results}

\section{Genotypic identification and accession denomination}


According to registration data, the 930 accessions included in this study have been received from 33 locations belonging to 10 countries. Four hundred and ninety-six (53.3\%) come from Spain, while 247 (26.6\%) come from Italy, France and Portugal. The rest of the countries were only represented by few accessions (between 1 and 25). In seven cases analysis of the two replicates per accession provided mismatching genotypes, so that the final number of analyzed accessions was 937 (Additional file 1). Accessions from locations in Andalusia rise to 101 (73 were hold at an earlier "Merced" collection established in 1940 in the current germplasm location), while the providing source is unknown for 153 (16.4\%) accessions. For 891 accessions, a profile match was found in the databases consulted (mainly VIVC, see M\&M). Table 1 shows a summary of the identification results. Wrong accession names were detected in 125 cases; in addition, 101 accession names did not correspond to any accepted denomination. Further verification should be performed to determine if they could be not yet recognized synonymies (Additional file 1). Four of the 46 accessions with an unidentified profile do not have any given accession name and another two shared the same genotype, so that 45 profiles remained unknown. Altogether, not duplicated genotypes were 350, while the rest (587) were clones or sports of at least one other accession. The total number of unique genotypes was 521 and their classification according to information provided by VIVC is shown in Table 1. Genotypes with an unknown utilization comprise the 45 unidentified profiles and cv. Gabriela. Twenty-three somatic mutants of 17 varieties and one from an interspecific cross were verified. In addition, four molecular variants (genotypes differing in just one allele) were detected for Colombard, Isabella (interspecific cross), and two accessions of Pinot Meunier. Finally, nine genotypes (including the two Pinot Meunier and four unidentified accessions) showed putative chimerism at least at one locus (see notes in Additional file 1).

The structure analysis combined with NJ on total unique genotypes (Additional file 5, figure A) suggests that two accessions, Ondarrabi Zuri and Churrín de Janeo, classified as vinifera in the VIVC, could be interbreeding crosses (IC) or were used to obtain them. For the former, in fact, Cabello et al. [21] clarify that a material identification mistake occurred in the "Finca el Encin" (Madrid) and that the accession present in this collection is indeed an IC, and not the true Ondarrabi Zuri, which is a vinifera cultivated in Northern Spain. For the latter, the two accessions whose profile matches with the putative vinifera Churrín de Janeo are denominated Híbrida and Híbrida Blanca, respectively ("híbrida" means hybrid in Spanish), and actually their morphological appearance confirms the assignation to IC (personal observation). All accessions grouping in SP7 (integrating admixed, see Additional file 3) should be considered non vinifera, except Khusaine Belyi, Dabouki and Morellone cvs and the accession named Patricia. Four IC, Gf.Ga.5242, Orion, Phoenix and Léon Millot, fits in sP6 (integrating admixed). We also excluded from the vinifera pool the accession Ikawa Opale (that groups in sP3) based on NJ and VIVC information. Finally, it is worth noting that Regent, Sirius, Phoenix and Staufer are commonly considered as vinifera varieties, but, based on strict botanical criteria, they are interbreeding crosses (see Additional file 1). To date, there is no international requisite to establish which percentage of vinifera genome is enough to assume an accession as a $V$. vinifera variety.

\section{Genetic structure}

The analysis of the genetic structure with STRUCTURE identified four main levels of stratification. The mean log-likelihood curve did not reach a plateau and the standard deviations did not increase drastically. However, from $\mathrm{K}=7$ the slope slightly decreased, and $\mathrm{L}(\mathrm{K})$ showed a tendency towards a plateau. The $\Delta \mathrm{K}$ criterion indicated $\mathrm{K}=2$ and $\mathrm{K}=7$ as the most pertinent levels of population subdivision (Additional file 2). Subsequent $\mathrm{K}$ levels were also explored (K=3 and $\mathrm{K}=5)$. Very few individuals could be strongly assigned $(\mathrm{Q} \geq 0.78)$ when more than seven inferred groups were considered. Therefore, we assumed that the germplasm collection analyzed here can be divided into seven subpopulations (sP 1-7) that represents the most complex stratification (Figure 1). Data obtained by STRUCTURE were combined with information concerning the geographical origin of each variety provided in the VIVC. This info has been assumed as the best option despite some inconsistences detected (see discussion). Within individuals displaying ancestry values above the chosen threshold $(\mathrm{Q} \geq 0.78)$, the sP1 comprises 73 genotypes, 44 of which are Spanish varieties mainly cultivated in the Central and Mediterranean regions, eight varieties are Portuguese, typically cultivated in the South-Central regions and only four are French (Additional file 3). The sP2 consists of 37 genotypes, mainly CentralEastern Mediterranean wine varieties, including 15 from Italy (mostly used in Southern regions), 13 from Balkans and four from Spain. The sP3 is predominantly composed by dual-use, including almost all table varieties of this collection, muscat flavor and some Sultanina related cultivars. The sP4 allocates Italian (mostly cultivated in the Northern regions) and French varieties, some of them are typical of Southern and Southeastern regions (Provence, Languedoc-Roussillon and Rhone Valley) and some others have an uncertain origin. The sP5 highlights 24 varieties from Portugal, especially cultivated in the North-Central regions, 14 from France, mainly originating in Western regions (Bordeaux, South West and Loire Valley), and 8 from Spain mostly distributed in Northern regions. The sP6 includes varieties from Central Europe and from France, most of them typical of the East-Central regions (Burgundy, Champagne and Alsace). Finally, the sP7 contains almost all non-vinifera genotypes, the only three recognized vinifera varieties clustering here were admixed. The percentage of admixed accessions ranges from $36 \%$ at $\mathrm{K}=2$ to $45 \%$ at $\mathrm{K}=7$.

In spite of the changes in the admixture levels, the comparison between different clustering steps showed that sP1 (mainly central-Mediterranean Iberian Peninsula varieties) together with sP2 (central-eastern Mediterranean wine varieties) clearly differentiate already at K=2 from sP4, sP6 and sP7 (which comprises mostly central Europe and non-vinifera genotypes); however, sP1 presented lower admixture than sP2. It is noteworthy that all 73 genotypes composing SP1 were already well discriminated from $\mathrm{K}=2$ through all the other $\mathrm{K}$ values explored till $\mathrm{K}=7$. Subpopulations sP3 (dual-use and table varieties) and SP5 (Northern Iberian Peninsula and Western France), that were mainly admixed for $\mathrm{K}=2$, got differentiated from $\mathrm{K}=3$. At $\mathrm{K}=5$ all subpopulations were discriminated except for SP4 (north Italy and southern France) and SP6 (Central Europe) which presented very high and moderate admixture levels, respectively (Figure 1)

The DAPC multivariate model, also performed with the unique genotypes, identified five groups as the best population subdivision. This clustering fitted fair well with the subpopulations obtained for K=7 in STRUCTURE. In fact, excluding SP7 (which includes rootstocks and interbreeding crosses), and sP4 (which contained a high level of admixture at $\mathrm{K}=5$ ), for a level of stratification DAPC $=5$ this new analysis was able to assign each cultivar to its respective subpopulation inferred with STRUCTURE at K = 7 with a fitness between $76 \%$ (sP5) and $100 \%$ (sP2) (Additional file 4; Table 2).

V. vinifera genotypes belonging to SP 1-6 were used to perform a NJ tree, which resulted consistent with STRUCTURE results (figure B in Additional file 5). An additional NJ tree was performed including the set of 101 cultivars with an eco-geographical origin inferred by Emanuelli et al. [10] according to Negrul [22] to 
visualize the distribution of the genotypes among Negrul's proles: pontica, orientalis and occidentalis (figures $\mathrm{C}$ to $\mathrm{H}$ in Additional file 5).

An additional geographical assignation of Portuguese and Spanish genotypes (Additional file 3; see M\&M) allowed performing STRUCTURE and DAPC analyses of the Iberian Peninsula germplasm, disclosing two and three genetic backgrounds, respectively. In both cases subpopulations were differentially distributed according to the area of origin/cultivation (Figure 2; Additional file 6). In fact, one subpopulation was exclusive of the central-west and northern area, but with an opposite representation pattern between North-west (NW) and North-east (NE). An opposite distribution pattern was also observed between South-west (SW) and South-east (SE) areas. Taking into account the analysis performed with STRUCTURE on the whole data set, genotypes within IBER 1/Q2 grouped mainly in SP5 (Northern Iberian Peninsula and Western France), while those within IBER 2 and IBER 3/Q1 grouped for the most part in sP1 (centralMediterranean Iberian Peninsula varieties).

\section{Genetic diversity and genetic differentiation}

These analyses were performed using the pool of $481 \mathrm{~V}$. vinifera genotypes. The PIC for each locus is shown in Table 3. The most polymorphic marker resulted to be MD28 while the least was ISV3. The second lowest value was for MD25, which showed only five alleles with frequency more than $1 \%$. Four markers (ZAG79, EVA2, VVS2 and MD28) showed the highest number of alleles (11) with frequency more than $1 \%$. ISV2 and ZAG79 presented, respectively, the most and the least number of rare alleles. Genetic diversity parameters are shown in Table 4. Cluster values of $\mathrm{H}_{\mathrm{e}}$ ranged from 0.695 to 0.809 with a clear increase when groups included admixed genotypes. $\mathrm{H}_{\mathrm{o}}$ was always higher than $\mathrm{H}_{\mathrm{e}}$ that means a slight excess of heterozygosity $(\mathrm{F}<0)$. The $\mathrm{PI}$ is around $10^{-}$

17 suggesting that identical genotypes with different denominations should correspond to synonyms. All AMOVAs performed with distinct pools (Figure $3 \mathrm{~A}$, B and $\mathrm{C}$ ) show a narrow differentiation among groups, being the total variance mostly dependent on differences within clusters. The $\mathrm{F}$ statistics confirm the excess of heterozygosity $\left(\mathrm{F}_{\mathrm{IS}}<0\right)$ remarking that individual loss of heterozygosity versus total population does not occur in any case. The Mediterranean Iberian sub-population (sP1) shows the closest genetic relationship with sP2, while the farthest is with sP6, given that sP7 has been excluded because of being mainly composed by non-vinifera individuals.

\section{Core collections}

Based on the M-method, thirty-five cultivars (core-35) were sufficient to capture all the 112 alleles occurring with a frequency more than $1 \%$. The core-35 was then used to design the final genetic core collection retaining $100 \%$ of SSR diversity, i.e. 168 alleles. The optimal size of this core was 63 individuals (core-63); thus 28 accessions were added at this step to retain 56 rare alleles (Additional file 3 ). In both collections, members from each inferred cluster by STRUCTURE at $\mathrm{k}=7$ are included, being the SP1 the most represented and SP6 and SP7 the least ones, as it could be expected according to different sP sizes (Table 5). Strikingly, sP2 is underrepresented in core-35 with respect to core-63 in which percentages between groups containing a major number of accessions (sP1, 2, 3,4 and 5) are more similar. Heterozygosity values are in the same range of the full collection and inferred clusters.

\section{Discussion}

\section{Genotypic identification and accession denominations}

Establishing the geographical origin and the correct prime name of a grapevine variety can become difficult due to the existence of a great number of synonyms and homonyms locally used, especially in the Mediterranean basin, as a result of the historical population displacements and migration through the centuries [3]. Therefore, population structure analyses such as those performed with STRUCTURE or Darwin software could be helpful to solve doubts about the correct geographical assignation. A consistent number of mislabeling and not verified denominations have been detected, as well as some discrepancies in allele size with respect to VIVC and other databases (Table 1 and Additional file 1). Despite VIVC is continuously updated, the volume of data managed is very huge and possibly still contains some not fully revised information collected before the GrapeGen06 SSR set was provided as a common SSR coding method. Some VIVC prime names of Spanish varieties do not correspond to the prime names reported in the commercial variety national catalogue (https://www.mapa.gob.es/app/regVar/ResBusVariedades.aspx?id=es\&TxtEspecie=VID\&IDEspecie=119) (e.g. Albillo Forastero instead of Forastera Blanca or Mouratón instead of Juan García). A list of changes will be privately suggested to JKl; in this work Blanca Gordal has been assigned for genotype 62 (Additional file 1) instead of Corazón de Cabrito (variety number VIVC 24550) since it was a clear mistake (personal observation).

Regarding the twenty-three somatic mutants found, eighteen are berry color sports, two are pulp pigmentation mutants (Gamay Teinturier de Bouze and G.T. Freaux) and three are leaf morphology sports (Additional file 1).

\section{Population structure, genetic diversity and genetic differentiation}

Grapevine collections maintained at many germplasm banks have been built over several decades through different networks of national and international partnerships. However, all of them are far to comprise all grapevine cultivars worldwide which are estimated to be approximately 10,000 held in field collections, in addition of an undefined number of local minority grapes not yet prospected [23]. Therefore, although several studies have explored the genetic information of these germplasm banks, no one could be fully conclusive about genetic structure of the entire cultivated grapevine gene pool (for review see [9]). The collection studied here is almost entirely composed by wine and dual-use varieties and about $75 \%$ of the accessions have supposedly been originated in Central and Western Europe. In any case, the genotype partitioning in STRUCTURE subgroups seems to be stable even when the data set analyzed presents an unbalanced repartition of genotypes from the different regional groups [9]. The vinifera pool of the grapevine collection characterized in this study showed a great $\mathrm{H}_{\mathrm{e}}$ (Table 3), similar to that displayed in larger collections $[9,10]$. In such high genetic variation conditions, only minimal gains in terms of total variability are possible through extending the genetic pool with entries from diverse eco-geographic sources [24]. Therefore, genetic structure and diversity studies may improve breeding programs. 
The $\Delta \mathrm{K}$ criterion give rise to the first structural level in the data [25] that depends on the nature of the samples analyzed. In the present study, the highest value was obtained for $\mathrm{K}=2$ (Additional file 2) that splitted up accessions cultivated in the Mediterranean climate from those of the Oceanic and Continental climates (Figure 1), unlike previous reports where SSRs at $\mathrm{K}=2$ distinguished among V. vinifera and non-vinifera [10], between subsp. vinifera and sy/vestris [26], or among proles and specific sub-proles [13] according to Negrul's classification [22]. At the next level of stratification (K=3) an additional cluster containing non-vinifera genotypes (RS, IC), table grapes and others with dual-use was pointed out. At K=5 and K=7 the grouping proposed by Negrul [22] was retraced with some additional partition. Varieties in SP2 (Central-Eastern Mediterranean wine varieties) and sP3 (dual-use and table varieties) essentially belong to proles pontica and orientalis respectively, and it is consistent with Darwin trees obtained combining our data with eco-geographic groups inferred at FEM [10] (figures $\mathrm{C}$ to $\mathrm{H}$ in Additional file 5). Interestingly, Tempranillo, the most cultivated variety in Spain, and Tinto Velasco, also very interesting in Andalusia for his flavor and drought adaptation, fit in sP2. According to Terral et al. [27], Tempranillo shows morphological similarities with some ancient French varieties; in our opinion, it could be related with the not fully disclosed origin of both Tempranillo parents, Albillo Mayor and Benedicto [28]. The origin of Tinto Velasco is still under investigation [21]. The sP4 is primarily composed by Northern Italy varieties and by some from Southeastern France, which are mainly admixed at $\mathrm{K}=5$. In particular, Italian genotypes presented a very high admixture percentage (Additional file 3 ) in each stratification level according to the weak structuration detected by Cipriani et al. [29]. French varieties also present high admixture level at $\mathrm{K}=5$ and $\mathrm{K}=7$. It is worth noting that they mostly split into sP4, 5 and 6 according to regional cultivation areas similarly to Aradhya et al. [24]. Instead, Spanish varieties show very low admixture levels, especially at $\mathrm{K}=2$ and 3, in disagreement with Bacilieri et al. [9] and Laucou et al. [30], although probably it depends on the nature and composition of the set of samples analyzed. Both Spanish and Portuguese cvs. mainly split into sP1 (Mediterranean Iberian Peninsula, mainly proles orientalis in NJ, figure C in Additional file 5) and sP5 (Northern Iberian Peninsula and Western France, proles occidentalis figure G in additional file 5), but the relative proportion is opposite, probably because in Spain as a whole prevails the Mediterranean climate whereas in Portugal prevails the Oceanic one. The constitution of sP1, that includes most of the Spanish varieties from Mediterranean climate, some Portuguese and few French ones, fits with the cluster identified in the largest grapevine collection worldwide by the 18k SNP genotyping array [30].

All $V$. vinifera groups inferred by STRUCTURE showed consistent genetic diversity $\left(\mathrm{H}_{\mathrm{e}}\right)$ in the same range of previous reports $[9,24,26]$. In all cases, the value increased only by less than $1 \%$ when the most permissive level of ancestry is considered (Table 4). Each group presented a slight excess of heterozygosity with respect to Hardy-Weinberg equilibrium that is supported by the negative values of $\mathrm{F}$. Only sP6 $\mathrm{H}_{\mathrm{e}}$ is slightly below 0.7 probably due to the low number of individuals with strong ancestry. The sP3 should be expected to have the biggest value because of the higher diversity contained in the proles orientalis [9], but probably, the number of individuals with Asiatic origin included in this collection is not enough to confirm this hypothesis. Portuguese cultivars presented the highest diversity among the main represented countries (Table 4). $\mathrm{F}_{\mathrm{ST}}$ values were statistically consistent. Nevertheless, only the general tendency can be compared with other studies because of the different definitions, estimation methods, and interpretations of $\mathrm{F}_{\mathrm{ST}}$ generate some confusion in the literature [31]. Mediterranean Spanish cvs. (sP1, mainly allocated within the proles orientalis-antasiatica in NJ, although some accessions laid within the proles pontica, figure $\mathrm{C}$ in Additional file 5) resulted genetically closer to Central-Eastern Mediterranean wine varieties (sP2, predominantly assigned to proles pontica figure D in additional file 5) than to other groups (Figure 3), and showed the highest divergence with Central European group (sP6, assigned to proles occidentalis figure $\mathrm{H}$ in Additional file 5, Figure 3). It should be noted that sP3, according to NJ, comprise individuals from both subproles caspica and antasiatica within proles orientalis (figure $\mathrm{E}$ in Additional file 5), and these genotypes are mainly related to muscats while those composing sP1 are mainly related with Heben cv. (Additional file 3). Bacilieri et al. [9] found a closer relation of Iberian cvs. with table East varieties than with Balkan ones, accordingly to Emanuelli et al. [10], whom cluster Spanish varieties into the proles orientalis-antasiatica. In the same study, hierarchical STRUCTURE by SNPs clearly separated Spanish cvs. from proles pontica. On the contrary, in Laucou et al. [30] Spanish varieties showed the lowest pairwise $\mathrm{F}_{\mathrm{ST}}$ with Balkan group that should be mainly composed by proles pontica and orientalis-caspica grapes [13]. Clustering methods and markers used can provide not fully consistent outcomes anyway $[9,24]$. In any case the hypothesis that Phoenician and Greeks introduced in Spain grapevines belonging to proles pontica and orientalis [22,32] is always corroborated. When separating groups by country of origin, Spain shows the lowest $\mathrm{F}_{\mathrm{ST}}$ versus Portugal (Figure 3), depending not only on geographical proximity but also on partition of both accession pools into sP1, sP2 (mainly admixed) and SP5 (Additional file 3), while similar $\mathrm{F}_{\mathrm{ST}}$ values are shown for pairwise Spain-Italy and Spain-France.

Differences among groups account for $10 \%$ of total genetic diversity in the strongly assigned accession sub-set $(Q \geq 0.78$, Figure $3 B$ ). When eco-geographic are referred to a less extended total area, this percentage tends to decrease [13,33], although a higher value was shown when comparing well-clustered wild and cultivated forms [26]. Genetic diversity within groups is almost totally due to the intra individual allelic variation, pointing out the high grapevine heterozygosity [3]. However, in our germplasm collection it seems that the scenario of a vinifera structure linked to a large complex pedigree with grape breeding restricted to a relatively small number of elite cultivars [34] has been further stressed by receiving preferentially selected genotypes throughout time. Extending AMOVA to admixed accessions, the extent of genetic diversity due to differentiation among sPs decreases as well as $\mathrm{F}_{\mathrm{ST}}$ from $\mathrm{F}$ statistics does (Figure 3B), indicating a low probability of genetic drift depending on geographical separation, especially when only the sub-area including Italy, France, Spain and Portugal is considered (Figure $3 \mathrm{C}$ ). These results, together with the consistent admixture levels in each $\mathrm{K}$ (Additional file 3 ) and the weak relationship between pairwise $\mathrm{F}_{\mathrm{ST}}$ comparison values and eco-geographic distances (Figure 3), support that the structure of modern grapevine population has been shaped by a long history of combination of natural hybridization, breeding, selection, human-mediated movements of seeds and cuttings and other factors, as it was proposed by Bacilieri et al. [9].

\section{Mediterranean Iberian Peninsula genetic pool}

Myles et al. [34] supported that domestication of Vitis vinifera subsp. sy/vestris into cultivated forms (subsp. vinifera) began 6,000-8,000 years ago in the Near East, and then grape growing and winemaking expanded westward toward Europe. Central and Western European grapevine groups showed some degree of genetic relationship with Eastern sy/vestris confirming an East-West gene flow by the movement of cultivated genotypes [35]. In addition, in these regions secondary domestication events involving local wild forms took place $[24,36,37]$. Given that wild and cultivated populations showed very close genetic diversity, Myles et al. [34] also suggested that many cultivars in use today may be only a small number of generations removed from the wild progenitor and

Page 5/16 
claimed that introgression occurred from Western sy/vestris to Western vinifera but not vice versa. It may explain why some ancient Central European varieties (proles occidentalis) as Clairette, Pinot Noir etc. conserve clear wild morphological traits [27,32,35]. Meanwhile Arroyo-García et al. [15] showed a major insertion of typical Eastern chlorotypes (especially C, D and E) in Italian, French and German varieties than in Spain, where the huge majority of both commercial varieties and still conserved wild types displayed the type A. Thus, at first sight, chlorotype indications seem to disagree from genetic relationships based on nuclear DNA markers, with the latter suggesting Spanish germplasm to be at least as close to Eastern genotypes as Italian, French and German ones are. A possible scenario is deducible from De Andrés et al. [26]: Spanish wild grapevines are essentially divided in two groups, Northern (NSW) and Southern (SSW), being the latest the most genetically closer to cultivated varieties. Individuals from SSW cluster separately from other wild forms at PCA in Myles et al. [34], while members of NSW group together with other sylvestris population. Interestingly, Eastern cultivated grapes are quite closer to SSW than to other European sylvestris. Myles et al. could not prove lack of introgression from Spanish cultivated grapes into SSW because of the very low number of Spanish cvs. included in that study. However, De Andrés et al. [26] detected a significant number of spontaneous vinifera-sy/vestris hybrids in Southern wild populations that could means gene-flow occurred in both directions (for example, Zalema cv. that is very important in Andalusia, showed a very close relation to sylvestris genotypes). Therefore, since Eastern grapevines were introduced in Spain by Phoenician and Greeks, putative repeated hybridization and backcrossing events between both subspecies may be supposed, resulting in the reduction of the genetic diversity among them (more than in other European areas) and obtaining new domesticated forms, without totally discarding the possibility that some primordial domestication had occurred even in former times $[38,39]$. Throughout this complex process, some female domesticated vines appeared and its fertilization with pollen from imported cultivars originated hybrids with oriental phenotypes conserving chlorotype A, as in the case of Hebén cv. that is an ancestor of many sP1 individuals and was shown previously to be a parent of several Spanish and Portuguese varieties [40]. Despite this hypothesis encloses some speculative elements, it is evident that sP1 accession pool originated by a consistent genetic contribution from oriental grapevines and a long-time interaction between wild and cultivated forms. Andalusia has surely represented a pivotal center of biodiversity development given that this region holds the main reservoir of Southern Spain wild vine populations [41] and Hebén, which was first described by Clemente y Rubio [42], has been cultivated in several areas within and close to Andalusia since very long time [21]. To delve into the question, determining the parents of Hebén, as well as the origin of other chlorotype A varieties, would be extremely helpful, given that it is a very hard issue often depending on lucky archaeobotanical findings [3]. Likewise, the discovery of the origin of Garnacha, that fits in sP1 and is a parent of some French varieties included in this cluster, would further clarify grape domestication and evolution in Western Europe. Finally, it worth mentioning that Eastern genotypes' contribution to Spanish grapevines is additionally proven by the presence of some accessions carrying the chlorotype D, as Palomino Fino, the main wine variety in Andalusia, and Jaén Tinto and Doradilla that are considered autochthonous of this region. Indeed, the type D chlorotype is common in wild forms eastward from Italy to Middle East [15] and its presence in Spain was previously discussed [23].

\section{Core collections}

Core-35 and -63 include $7.3 \%$ and $13.1 \%$ of the total accessions of the collection, respectively, being these results in accordance with previous studies [43]. These cores are consistent because include an acceptable percentage of each cluster inferred by structure analysis (Table 5). Therefore, they may be suitable for future association studies or at least provide an idea about the optimal size and cluster composition. However, when a specific study will be engaged, the real objective of the working core collection must be carefully analyzed and consequently some additional questions should be taken into account: a) the possibility of including phenotypic traits of agronomical and/or commercial interest, b) the chance of genotype-phenotype covariance due to individual relatedness, which should be avoided by removing/substituting some accessions [44], and c) the possibility of including a priori in the kernel file of MSTRAT some key varieties (e.g. Pinot Noir, Merlot and Sangiovese) which are excluded by the present analysis. Finally, we remark the presence in both cores of individuals from sP7, given that only 4 accessions within this cluster are putative Vitis vinifera.

\section{Conclusions}

The genetic characterization of this grapevine collection conserved at Rancho de la Merced has allowed to identify mislabeling and redundant accessions, somatic and molecular variants, as well as new grapevine genetic resources. These results will help to optimize the management of one of the most important international grapevine germplasm's banks. In addition, the information obtained could assess an important updating of the VIVC. A consistent genetic diversity has been revealed in both the full Vitis vinifera pool and the clusters inferred by structure analysis. Two main stratification levels have been pointed out, the former discriminating grapes cultivated in Mediterranean climate from Continental-Oceanic ones, and the latest depending on more restricted ecogeographic areas of cultivation. A Core collection capturing all allele richness may be suitable for association studies given that an equilibrated accession contribution from each of the six main eco-geographic inferred groups was achieved. Varieties from Iberian Peninsula cultivated under Mediterranean conditions form a quite genetically homogenous group and, in accordance to previous studies, our results confirm that the origin of many Spanish (and Andalusian) varieties is strongly related to both local Vitis sylvestris and Eastern Vitis vinifera cultivars introduced in Spain by trade.

\section{Materials And Methods}

\section{Plant material}

The grapevine germplasm bank "Rancho de la Merced" is located at the homonym IFAPA center, occupying approximately a 3,5 ha surface area (google maps location link:

https://www.google.es/maps/place/IFAPA+Center+Rancho+la+Merced/@36.72794,6.1658487,17z/data=!3m1!4b1!4m5!3m4!1s0xd0dc3fd6b941443:0x6e5dC 6.16366). It contains about 1800 accessions including Vitis vinifera subp. vinifera and sy/vestris, other Vitis species, rootstocks (RS) and interspecific crossing or hybrids direct producers (IC or HPD). Each accession is contained in a sub-plot consisting of five clonal replicates obtained by grafting buds of a given mother plant on RS 161-49 Couderc. For most of the accessions following data are available: accession name, country and center that provided cuttings, year of reception, phenology (budburst, flowering, veraison and harvest), must quality (yield, pruning weight, Baumé and titratable acidity), use and skin 
color [16]. In this paper we studied all accessions contained in the section designated to conserve wine Vitis vinifera varieties, composed by 930 sub-plots. Two vines out of five clonal replicates per accession were analyzed, although in some cases only one plant was available.

\section{Microsatellite Analysis}

DNA was extracted from $0.05 \mathrm{~g}$ of fresh young leaves using the DNeasy 96 Plant Kit (Qiagen) with a slight modification consisting in the addition of a pinch of polyvinylpyrrolidone PVP 40.000 to the extraction buffer. DNA yield and quality were determined by NanoDrop ND-1000 spectrophotometer (NanoDrop Technologies). In some cases, quality was further checked in $1 \%$ agarose gels after RedSafe ${ }^{\mathrm{TM}}$ staining under UV light and, for poor quality DNA samples, reextraction was performed by DNeasy Plant Mini Kit (Qiagen) on $0.1 \mathrm{~g}$ young leaves frozen in liquid nitrogen. Thirteen SSR markers were analyzed, the nine included in the GrapeGen06 set (see introduction) and four others (ISV2, ISV3, ISV4, and VMCNG4b9) that are routinely used at CREA-UTV (Turi, Italia, [45]). Four multiplex PCR were set up in a $10 \mu \mathrm{L}$ vol containing less than $50 \mathrm{ng}$ of DNA, 5 pmol of each forward and reverse primer and $5 \mu \mathrm{L}$ of DNA Amplitools Master Mix (Biotools). Forward primers were labelled with WellRED dyes D2-PA, D3-PA or D4-PA (Sigma-Aldrich) at the 5' end. The cycling profile consisted of an initial heat activation step at $96^{\circ} \mathrm{C}$ for $3 \mathrm{~min}, 36$ cycles of denaturation at $94^{\circ} \mathrm{C}$ for $20 \mathrm{~s}, 30 \mathrm{~s}$ annealing at temperatures ranging from 56 to $63^{\circ} \mathrm{C}$ depending on the lowest primer melting temp., and extension at $72{ }^{\circ} \mathrm{C}$ for $50 \mathrm{~s}$, and a final extension step at $72{ }^{\circ} \mathrm{C}$ for 15 min. Amplicons were separated on a GenomeLab ${ }^{\mathrm{TM}}$ GeXP Genetic Analysis System (Beckman Coulter) and sized using the manufacturer's software. Alleles occurring less than six times were carefully checked by electropherogram visual inspection and errors were corrected accordingly. Profiles of reference varieties Garnacha, Merlot, Shiraz and Gewürztraminer were used to harmonize SSR allele sizes and compare genotypes with the Vitis International Variety Catalogue (VIVC). Profile comparison was extended to other Vitis databases when no match was found in VIVC: the Grapevine Collection at "Fondazione Edmund Mach" (FEM, ITA362), the Germplasm Repository at the CREA-VIT of Conegliano (ITA388, [46]), the Italian Vitis Database (http://www.vitisdb.it/), The IMIDRA Grapevine Germplasm Collection (ESP080, https://www.comunidad.madrid/info/coleccion-vid?nombre_local=palomino\&nombre_principal=\&nombre_local_exact=\&nombre_principal_exact=), the Italian Grapevine Variety National Register (http://catalogoviti.politicheagricole.it/result.php?codice=315), the variety collection at Canarias Islands (http://vitiscanarias.com/) and the Grapevine Variety Collection at IVICAM (ESP216,

http://pagina.jccm.es/ivicam/servicios/microsatelites/microsatelites.php). In addition, for the GrapeGen06 SSR set, data were coded for comparability of microsatellite profiles according to Maul et al. [47] in order to be included in the European Vitis Database (http://www.eu-vitis.de/index.php).

\section{Analysis of the data}

The main variety name, the use, and the country of origin to each identified genotype was assigned according to the information given on the databases consulted (see above), mainly VIVC. No matching genotypes as well as missing information were annotated as "unidentified".

The genetic stratification of the germplasm under study - considering just the unique genetic profiles detected - was explored through different statistical methods.

A Bayesian clustering algorithm to sort individuals into K clusters (subpopulations) according to their genetic similarity was performed using STRUCTURE 2.3.4 [48]. The best $\mathrm{K}$ is chosen based on the estimated membership coefficients ( $Q$ ) for each individual in each cluster. Ten independent runs for $K$ values ranging from 1 to 15 were performed with a burn-in length of 500000 followed by 750000 iterations. The admixture model with correlated allele frequencies was assumed and no prior population information was set up. The membership coefficient threshold defined for individual assignment to a given cluster was $\mathrm{Q}=0.78$. STRUCTURE HARVESTER 0.6 .93 [49] was used for visualizing STRUCTURE output and inferring the most likely subdivision (K) by: a) plotting the log probability $\mathrm{L}(\mathrm{K})$ following plateau criterion proposed by Pritchard and Falush [50] and b) by $\Delta \mathrm{K}$ method according Evanno et al. [51]. Additional data analysis and formatting was subsequently applied to STRUCTURE results with CLUMPP [52] and DISTRUCT [53]. CLUMPP permutes the clusters output by the 10 independent runs of STRUCTURE, so that the clusters align across runs, while DISTRUCT allows the graphical representation of the aligned cluster assignments for a single $\mathrm{K}$ value. CLUMPAK [54] was used to align single results obtained for different $\mathrm{K}$ values $(2,3,5$ and 7$)$. These single results consisted of averages obtained with CLUMPP for multiple independent runs.

Data were also evaluated using the Poppr package [55] in R (3.1.3 version, https://www.r-project.org). Initially the SSR dataset was examined by using the discriminant analysis of principal components (DAPC) implemented in the "Adegenet package ver. 2.0.1 [56,57]. Prior clusters were identified by a sequential K-means clustering algorithm (find.clusters function) after data transformation by principal component analysis (PCA). Then, a discriminant analysis (DA) used part of the principal components (PCs) to describe the clusters. K-means was run with K varying from 1 to 20 and to ensure convergence we increased the number of starting points to 200. The number of clusters was chosen based on the Bayesian Information Criterion (BIC) [58]. In order to avoid retaining too many dimensions at the DA step, the optimal number of PCs was computed by using both "optim.a.score" and "xvalDapc" functions from "adegenet". The final cluster assignment was obtained after the DA analysis.

Finally, an unweighted neighbour-joining $(\mathrm{NJ})$ tree was constructed based on Simple Matching dissimilarity index (SM) between the unique genetic profiles using Darwin software package v6.0 [59]. One thousand bootstrap replicates were performed. A further cluster analysis with Darwin was performed including 101 varieties with a clear ancestry inferred by Emanuelli et al. [10] in accordance with the eco-geographic origin of the cultivars [22]. In this case only the nine SSR markers analyzed in common for both data sets were considered (VVS2, VVMD5, VVMD7, VVMD25, VVMD27, VVMD28, VVMD32, VrZAG62 and VrZAG79). The germplasm from the Iberian Peninsula was further explored by both STRUCTURE and DAPC analysis as described above. Genotypes from Spain and Portugal were assigned to a geographic area of origin and/or cultivation within the lberian Peninsula corresponding to six pre-stablished areas: North-west (NW), North-east (NE), Central-west (CW), Central-east (CE), South-west (SW), South-east (SE), CAN (Canary Islands) and BAL (Balearic Islands)

Genetic diversity analyses were conducted on the pool of Vitis vinifera genotypes. Following statistics were determined with GenAlEx 6.0 [60]: number of alleles (Na), mean number of alleles per locus (MNA), effective number of alleles (Ne), observed heterozygosity (Ho), expected heterozygosity (He), Fixation Index (F), also called inbreeding coefficient, and the probability of identity (PI). The Excel add-in Microsatellite Toolkit [61] was used to determine the 
polymorphism information content (PIC). All these parameters were obtained for: a) the overall Vitis vinifera population; b) for the main country groups according to VIVC information; c) for each cluster pointed out by STRUCTURE. We also studied the hierarchical genetic variation among and within inferred subpopulations by AMOVA and their genetic differentiation by the F-statistic $\left(\mathrm{F}_{\mathrm{IS}}, \mathrm{F}_{\mathrm{ST}}\right.$, and $\mathrm{F}_{\mathrm{IT}}$, where I means individuals, $\mathrm{S}$ subpopulations and $\mathrm{T}$ the total population), including the calculation of $\mathrm{F}_{\mathrm{ST}}$ for each group pairwise comparison.

Two genetic core collections of the vinifera set were constructed using the M (maximization) method, suggested by Schoen and Brown [62] and implemented in MSTRAT [63]. In the former rare alleles (less than 1\% frequency) were discarded; in the latest all alleles were considered while fixing in the kernel file all accessions needed for the former. The redundancy step was previously performed to have an indication about the core collection size ( $\mathrm{n}$ ), setting 20 replicates, 200 iterations and Nei index as criterion of maximization. Then, core constructions were obtained testing different putative core size setting 100 replicates and 200 iterations. The final size was the lowest " $n$ " that means the corresponding most represented " $n$ " genotypes within the 100 replicates were able to capture all allele richness searched.

\section{Abbreviations}

AMOVA $=$ Analysis of Molecular Variance; CREA (-UTV \&-VIT) = Consiglio per la Ricerca in Agricoltura e l'analisi dell'Economia Agraria (Uva da Tavola \& Viticultura ed Enologia); DAPC = Discriminant Analysis of Principal Components; DNA = DeoxiriboNucleic Acid; IC = Interspecific Crossing; IMIDRA = Instituto Madrileño de Investigación y Desarrollo Rural, Agrario y Alimentario; INRA = Institut National de la Recherche Agronomique; IVICAM = Instituto de la Vid y el Vino de Castilla la Mancha; NJ = Neighbor Joining; RS = Rootstocks; SSR = Simple Sequence Repeat; SNP = Single Nucleotide Polimorphism VIVC = Vitis International Variety Catalogue;

\section{Declarations}

\section{Ethics approval and consent to participate}

Not applicable.

\section{Consent for publication}

Not applicable.

\section{Availability of data and materials}

The datasets generated during the current study are not publicly available yet. Full accession information is stored at informatic resources of IFAPA center "Rancho de la Merced" and authors will be glad to provide any data required for research purposes.

\section{Competing interests}

The authors declare that they have no competing interests.

\section{Funding}

This work was supported by IFAPA projects AVA201301.3 and AVA201601.3, co-funded by FEDER and INIA project RFP2014-00002-00-00, co-funded by FEDER. Paula Moreno Sanz's research grant was funded by Fondazione CARITRO, project 2017.0349.

\section{Authors' contributions}

EC conceived the study, carried out SSR analysis constructed core collections, performed population structure analysis, and drafted part of the manuscript. PMS carried out genetic diversity analyses, participated in the design of the study, achieved structure and DAPC graphics, and drafted part of the manuscript. SL managed the data produced by SSR analysis and helped in the discussion of results. LV provided lab assistance and helped in sampling, SSR analyses and discussion of results. MLB managed registration data of accessions, performed phenotyping observations and helped in discussion of results. FE participated in the design of the study, supervised results, conducted DAPC analysis, and wrote part of the manuscript. All authors read and approved the final manuscript.

\section{Acknowledgments}

The authors would also thank to Maria J. Alcalá Ramirez (IFAPA) for technical assistance, José Antonio Perez Ortíz (IFAPA) for his assistance in sampling, Yolanda Verdún Domínguez (CSIC) for sequentiation assistance, José Francisco Sánchez Sevilla (IFAPA) for his suggestions in data analysis, and Axel for his invaluable company.

\section{Authors' Information}

${ }^{1}$ Instituto de Investigación y Formación Agraria y Pesquera (IFAPA), Centro Rancho de la Merced, Carretera Cañada de la Loba (CA-3102) PK 3.1, 11471 Jerez de la Frontera, Spain

${ }^{2}$ Research and Innovation Center, Fondazione Edmund Mach (FEM), Via E. Mach 1, 38010 San Michele all'Adige, Italy 
${ }^{3}$ Center Agriculture Food Environment, University of Trento, Via E. Mach 1, 38010 San Michele all'Adige, Italy.

${ }^{4}$ Instituto de Investigación y Formación Agraria y Pesquera (IFAPA), Centro de Málaga, Cortijo de la Cruz s/n, 29140 Málaga, Spain

\section{References}

1. FAO. Genebank Standards for Plant Genetic Resources for Food and Agriculture. 181 pp. 2013. http://www.fao.org/3/i3394e/i3394e.pdf

2. OIV. State of the world vitivinicultural sector in 2019. 15 pp. 2020. https://www.oiv.int/public/medias/7298/oiv-state-of-the-vitivinicultural-sector-in2019.pdf

3. This P, Lacombe T, Thomas MR. Historical origins and genetic diversity of wine grapes. Trends Genet. 2006;22(9):511-519

4. Maul E, Sudharma K N, Ganesh A, Hundemer M, Kecke S, Marx G, Schreiber T, Walk M, Vom Weg S, Mahler-Ries A, BrühI U, Töpfer R. 30 Years VIVC - Vitis International Variety Catalogue (www.vivc.de). 2014. XI International Conference on Grapevine Breeding and Genetics, Yanqing, Beijing, China

5. This P, Jung A, Boccacci P, Borrego J, Botta R, Costantini L, Crespan M, Dangl GS, Eisenheld C, Ferreira-Monteiro F, Grando MS, Ibáñez J, Lacombe T, Laucou V, Magalhaes R, Meredith CP, Milani N, Peterlunger E, Regner F, Zulini L, Maul E. Development of a standard set of microsatellite reference alleles for identification of grape cultivars. Theor Appl Genet. 2004;109(7):1448-1458

6. Dangl GS, ML Mendum BH Prins MA Walker CP Meredith, Simon CJ. Simple sequence repeat analysis of a clonally propagated species: A tool for managing a grape germplasm collection. Genome 2001;44:432-438

7. Zarouri B, Vargas A M, Gaforio L, Aller M, De Andrés MT, Cabezas JA. 2015. Whole-genome genotyping of grape using a panel of microsatellite multiplex PCRs. Tree Genetics \& Genomes 2015;11:17

8. Lacombe T, Boursiquot JM, Laucou V, Di Vecchi-Staraz M, Péros JP, This P. Large-scale parentage analysis in an extended set of grapevine cultivars (Vitis vinifera L.). Theor Appl Genet. 2013;126:401-414

9. Bacilieri R, Lacombe T, Le Cunff L, Di Vecchi-Staraz M, Laucou V, Genna B, Péros JP, This P, Boursiquot JM. Genetic structure in cultivated grapevines is linked to geography and human selection. BMC Plant Biol. 2013;13(1):25

10. Emanuelli F, Lorenzi S, Grzeskowiak L, Catalano V, Stefanini M, Troggio M, Grando MS. Genetic diversity and population structure assessed by SSR and SNP markers in a large germplasm collection of grape. BMC Plant Biol. 2013;13(1):39

11. Van Hintum ThJL, Brown AHD, Spillane C, Hodgkin T. Core collections of plant genetic resources. IPGRI Technical Bulletin 3. 2000

12. De Oliveira GL, De Souza AP, De Oliveira FA, Zucchi MI, De Souza LM, Moura MF. Genetic structure and molecular diversity of Brazilian grapevine germplasm: Management and use in breeding programs. PlosOne 2020;15(10): e0240665

13. Štajner N, Tomić L, Ivanišević D, Korać N, Cvetković-Jovanović T, Beleski K, Angelova E, Maraš V, Javornik B. Microsatellite inferred genetic diversity and structure of Western Balkan grapevines (Vitis vinifera L.). Tree Genet Genomes 2014;10(1):127-140

14. Le Cunff L, Fournier-Level A, Laucou V, Vezzulli S, Lacombe T, Adam-Blondon AF, Bourisquot J-M, This P. Construction of nested genetic core collections to optimize the exploitation of natural diversity in Vitis vinifera L. subsp. sativa. BMC Plant Biol. 2008;31:8

15. Arroyo-García R, Ruiz-García L, Bolling L, Ocete R, López MA, Arnold C, Ergul A, Söylemezoğlu G, Uzun HI, Cabello F, Ibáñez J, Aradhya MK, Atanassov A, Atanassov I, Balint S, Cenis JL, Costantini L, Goris-Lavets S, Grando MS, Klein BY, McGovern PE, Merdinoglu D, Pejic I, Pelsy F, Primikirios N, Risovannaya V, Roubelakis-Angelakis KA, Snoussi H, Sotiri P, Tamhankar S, This P, Troshin L, Malpica JM, Lefort F, Martinez-Zapater JM. Multiple origins of cultivated grapevine (Vitis vinifera L. ssp. sativa) based on chloroplast DNA polymorphisms. Mol Ecol. 2006:15(12):3707-3714

16. García de Luján A, Lara Benítez M. La colección de vides del Rancho de la Merced. 157 pp. 1997.Junta de Andalucía (Spain)

17. Laucou V, Lacombe T, Dechesne F, Siret R, Bruno JP, Dessup M, This P. High throughput analysis of grape genetic diversity as a tool for germplasm collection management. Theor Appl Genet. 2011;122(6):1233-1245

18. Junta de Andalucía. El sector del vino andaluz en cifras. Secretaría general de agricultura y alimentación. 61 pp. 2017

19. Tóth JP, Végvári Z. Future of winegrape growing regions in Europe. Aust J Grape Wine Res. 2016;22(1):64-72

20. Agustí-Brisach C, López-Moral A, Carmen Raya-Ortega MC, Franco R, Roca-Castillo LF, Trapero A. Occurrence of grapevine trunk diseases affecting the native cultivar Pedro Ximénez in southern Spain. Eur J Plant Pathol. 2019;153:599-625

21. Cabello F, Ortiz JM, Muñoz-Organero G, Rodríguez-Torres I, Barba AB, Rubio de Miguel C, García-Muñoz S, De Andrés MT, Sáiz R. 522 pp. 2019. Variedades de vid en España, $2^{\circ}$ edición. Editorial Agrícola Española, S.A.

22. Negrul AM. Evolution of cultivated forms of grapes. CR Acad Sci USSR 1938;18:585-588

23. García-Muñoz S, Lacombe T, de Andrés MT, Gaforio L, Muñoz-Organero G, Laucou V, This P, Cabello F. Grape varieties (Vitis vinifera L.) from the Balearic Islands: Genetic characterization and relationship with Iberian Peninsula and Mediterranean Basin. Genet Resour Crop Evol. 2012;59(4):589-605

24. Aradhya MK, Dangl GS, Prins BH, Walker MA, Meredith CP. Genetic structure and differentiation in cultivated grape, Vitis vinifera L. Genet Res. 2003;81(3):179-192

25. Lia VV, Poggio L, Confalonieri VA. Microsatellite variation in maize landrace from Northwestern Argentina: genetic diversity, population structure and racial affiliation. Theor Appl Genet. 2009;119(6):1053-1067

26. De Andrés MT, Benito A, Pérez-Rivera G, Ocete R, Lopez MA, Gaforio L, Muñoz-Organero G, Cabello F, Martínez-Zapater JM, Arroyo-García R. Genetic diversity of wild grapevine populations in Spain and their genetic relationship with cultivated grapevines. Mol Ecol. 2012;21(4):800-816

27. Terral JF, Tabard E, Bouby L, Ivorra S, Pastor T, Figueiral I, Picq S, Chevance JP, Jung C, Fabre L, Tardy C, Compan M, Bacilieri R, Lacombe T, This P. Evolution and history of grapevine (Vitis vinifera) under domestication: new morphometric perspectives to understand seed domestication syndrome and

Page 9/16 
reveal origins of ancient European cultivars. Ann Bot. 2010;105(3):443-455

28. Ibañez J, Muñoz-Organero G, Zinelabidine LH, De Andrés MT, Cabello F, Martínez-Zapater JM. Genetic origin of the grapevine cultivar Tempranillo. Am J Enol Vitic. 2012;63(4):549-553

29. Cipriani G, Spadotto A, Jurman I, Di Gaspero G, Crespan M, Meneghetti S, Frare E, Vignani R, Cresti M, Morgante M, Pezzotti M, Pe E, Policriti A, Testolin R. The SSR-based molecular profile of 1005 grapevine (Vitis vinifera L.) accessions uncovers new synonymy and parentages, and reveals a large admixture amongst varieties of different geographic origin. Theor Appl Genet. 2010;121(8):1569-1585

30. Laucou V, Launay A, Bacilieri R, Lacombe T, Adam-Blondon AF, Bérard A, Chauveau A, de Andrés MT, Hausmann L, Ibáñez J, Le Paslier MC, Maghradze D, Martinez-Zapater JM, Maul E, Ponnaiah M, Töpfer R, Péros JP, Boursiquot JM. Extended diversity analysis of cultivated grapevine Vitis vinifera with $10 \mathrm{~K}$ genome-wide SNPS. PLoS One 2018;13(2)

31. Bhatia G, Patterson N, Sankararaman S, Price AL. Estimating and interpreting FST: The impact of rare variants. Genome Res. 2013;23(9):1514-1521

32. Levadoux L. Les populations sauvages et cultivées de Vitis vinifera L. Annales de l'amélioration des plantes 1956;6:59-118

33. Imazio S, Maghradze D, de Lorenzis G, Bacilieri R, Laucou V, This P, Scienza A, Failla O. From the cradle of grapevine domestication: Molecular overview and description of Georgian grapevine (Vitis vinifera L.) germplasm. Tree Genet Genomes 2013;9(3):641-658

34. Myles S, Boyko AR, Owens CL, Brown PJ, Grassi F, Aradhya MK, Prins B, Reynolds A, Chia JM, Ware D, Bustamante CD, Buckler ES. Genetic structure and domestication history of the grape. PNAS 2011;108(9):3530-3535

35. Magris G. Jurman I. Fornasiero A. Paparelli E. Schwope R. Marroni F. Di Gaspero G. Morgante, M. The origin of European wine grapes. Nat Commun. $2021 ; 12: 7240$

36. Grassi F, Labra M, Imazio S, Spada A, Sgorbati S, Scienza A, Sala F. Evidence of a secondary grapevine domestication centre detected by SSR analysis. Theor Appl Genet. 2003;107(7):1315-1320

37. Barnaud A, Laucou V, This P, Lacombe T, Doligez A. Linkage disequilibrium in wild French grapevine, Vitis vinifera L. subsp. silvestris. Heredity 2010;104(5):431-437

38. Stevenson AC. Studies in the Vegetational History of S.W. Spain. II. Palynological Investigations at Laguna de las Madres, S.W. Spain. J Biogeogr. 1985;12(4):293-314

39. Hopf M. Plant remains from Bogazköy, Turkey. Rev Palaeobot Palyno. 1992;73(1-4):99-104

40. Zinelabidine LH, Cunha J, Eiras-Dias JE, Cabello F, Martínez-Zapater JM, Ibáñez J. Pedigree analysis of the Spanish grapevine cultivar 'Hebén'. Vitis 2015;54(Special):81-86

41. Cantos M, Arroyo-García R, García JL, Lara M, Morales R, López MÁ, Gallardo A, Ocete CA, Rodríguez Á, Valle JM, Vaca R, González-Maestro M, Bánáti $\mathrm{H}$, Ocete R. Current distribution and characterization of the wild grapevine populations in Andalusia (Spain). C R Biol. 2017;340(3):164-177

42. Clemente y Rubio S de R. Ensayo sobre las variedades de la vid común que vegetan en Andalucía: con un índice etimológico y tres listas de plantas en que se caracterizan varias especies nuevas. 325 pp. 1807.Imprenta de Villalpando, Madrid (Spain)

43. Vargas AM, de Andrés MT, Ibañez J. Maximization of minority classes in core collections designed for association studies. Tree Genet Genomes 2016;12(2):28

44. Myles S, Peiffer J, Brown PJ, Ersoz ES, Zhang ZW, Costich DE, Buckler ES. 2009. Association mapping: critical considerations shift from genotyping to experimental design. Plant Cell 2009;21(8):2194-2202

45. Bergamini C, Caputo AR, Gasparro M, Perniola R, Cardone MF, Antonacci D. Evidences for an alternative genealogy of "Sangiovese". Mol Biotechnol. 2013;53(3):278-288

46. Gardiman M, Bavaresco L. The Vitis Germplasm Repository at the CRA-VIT, Conegliano (Italy): Conservation, Characterization and Valorisation of Grapevine Genetic Resources. Acta Hort. 2015;1082:239-244

47. Maul E, Sudharma KN, Kecke S, Marx G, Müller C, Audeguin L, Boselli M, Boursiquot JM, Bucchetti B, Cabello F, Carraro F, Crespan M, De Andrés MT, Dias JE, Ekhvaia J, Gaforio L, Gardiman M, Grando MS, Gyropoulos D, Jandurova O, Kiss E, Kontic J, Kozma P, Lacombe T, Laucou V, Legrand D, Maghradze D, Marinoni D, Maletic E, Moreira F, Muñoz-Organero G, Nakhutsrishvili G, Pejić I, Peterlunger E, Pitsoli D, Pospíšilová D, Preiner D, Raimondi S, Regner F, Savin G, Savvides S, Schneider A, Sereno C, Simon S, Staraz M, Zulini L, Bacilieri R, This P. 2012. The European Vitis Database (http://www.eu-vitis.de): a technical innovation through an online uploading and interactive modification system. Vitis 2012;51(2):79-85

48. Pritchard JK, Stephens M, Donnelly P. Inference of population structure using multilocus data. Genetics 2000;155(2):945-959

49. Earl DA, vonHoldt BM. Structure Harvester: a website and program for visualizing structure output and implementing the Evanno method. Conserv Genet Resour. 2012;4(2):359-361

50. Pritchard JK, Falush D. Documentation for Structure Software: Version 2.2. University of Chicago, USA. 2007

51. Evanno G, Regnaut S, Goudet J. Detecting the number of clusters of individuals using the software STRUCTURE: a simulation study. Mol Ecol. 2005;14(8):2611-2620

52. Jakobsson M, Rosenberg NA. CLUMPP: a cluster matching and permutation program for dealing with label switching and multimodality in analysis of population structure. Bioinformatics 2007;23(14):1801-1806

53. Rosenberg NA. DISTRUCT: a program for the graphical display of population structure. Mol Ecol. 2004;4(1):137-138

54. Kopelman NM, Mayzel J, Jakobsson M, Rosenberg NA, Mayrose I. Clumpak: A program for identifying clustering modes and packaging population structure inferences across K. Mol Ecol Resour. 2015;15(5):1179-1191 
55. Kamvar ZN. Tabima JF. Grünwald NJ. (2014). Poppr: an R package for genetic analysis ofpopulations with clonal, partially clonal, and/or sexual reproduction. PeerJ 2014;DOI 10.7717/peerj.281

56. Jombart T, Devillard S, Dufour AB, Pontier D. Revealing cryptic spatial patterns in genetic variability by a new multivariate method. Heredity 2008;101:92103

57. Jombart T, Devillard S, Balloux F. Discriminant analysis of principal components: A new method for the analysis of genetically structured populations. BMC Genetics 2010;11(1):94

58. Schwarz G. Estimating the dimension of a model. Ann Stat. 1978;6(2):461-464

59. Perrier X, Jacquemoud-Collet JP. DARwin software. 2006. http://darwin.cirad.fr/

60. Peakall R, Smouse PE. GenAlEx 6.5: genetic analysis in Excel. Population genetic software for teaching and research - an update. Bioinformatics 2012;28(19):2537-2539

61. Park SJ. Microsatellite Toolkit for Excel. Smurfit Institute of Genetics, Trinity College, University of Dublin, Ireland. 2001

62. Schoen DJ, Brown AH. Conservation of allelic richness in wild crop relatives is aided by assessment of genetic markers. PNAS 1993;90(22):10623-10627

63. Gouesnard B, Bataillon TM, Decoux G, Rozale C, Schoen DJ, David JL. MSTRAT: An Algorithm for Building Germ Plasm Core Collections by Maximizing Allelic or Phenotypic Richness. J Hered. 2001;92(1):93-94

\section{Tables}

Table 1. Accession and genotype categorization

\section{ACCESSIONS}

Identified

$\begin{array}{lll}\text { Correct } & \text { Verified } & \text { Not verified } \\ \text { accession } & \text { synonymies* } & \text { synonymies }\end{array}$

name

264

358

$\begin{array}{lll}\text { Without } & \text { Wrong } & \text { Total } \\ \text { accession } & \text { accession } & \text { identified }\end{array}$

name name

43
125
891

$\begin{array}{ll}\text { Unidentified } & \begin{array}{l}\text { Total } \\ \text { analyzed }\end{array}\end{array}$

\section{GENOTYPES}

$\begin{array}{lll}\text { SSR } & \text { SSR } & \text { Different SS }\end{array}$

represented Total Win accession

by two or

accessions

$350 \quad 587$

521

297

* Most are reported in the VIVC, others are indicated by Cabello et al. (2019) or in commercial variety catalogues (https://www.mapa.gob.es/app/regVar/)

Table 2. Distribution of varieties assigned at $K=7$ in the other STRUCTURE stratifications and DAPC analysis

\begin{tabular}{|c|c|c|c|c|c|c|c|c|c|}
\hline \multirow{3}{*}{$\begin{array}{l}\text { STRUCTURE } \\
\mathrm{K}=7\end{array}$} & \multicolumn{9}{|c|}{ Genotypes with ancestry $(Q)>0.78$} \\
\hline & group & sP1 & sP2 & sP3 & sP4 & sP5 & sP6 & sP7 & Total \\
\hline & genotypes & 73 & 37 & 42 & 35 & 51 & 23 & 23 & 284 \\
\hline
\end{tabular}

\section{Assigned in other STRUCTURE $K$ and DAPC}

Not

assigned

$(Q<0,78)$

\begin{tabular}{|c|c|c|c|c|c|c|c|c|c|c|}
\hline & & & & & & & & & $\underline{\text { Total }}$ & \\
\hline \multirow{3}{*}{$\begin{array}{l}\text { STRUCTURE } \\
Q \geq 0.78\end{array}$} & $K=2$ & $73 / 0$ & $23 / 0$ & $9 / 7$ & $0 / 30$ & $2 / 26$ & $0 / 20$ & $0 / 17$ & 207 & 77 \\
\hline & $K=3$ & $72 / 0 / 0$ & $8 / 1 / 0$ & $0 / 33 / 0$ & $0 / 0 / 16$ & $0 / 0 / 42$ & $0 / 0 / 14$ & $0 / 21 / 0$ & 207 & 77 \\
\hline & $K=5$ & $73 / 0 / 0 / 0 / 0$ & 0/29/0/0/0 & $0 / 0 / 41 / 0 / 0$ & $0 / 4 / 2 / 2 / 0$ & $0 / 0 / 0 / 48 / 0$ & 0/0/0/1/17 & $0 / 0 / 0 / 0 / 22$ & 239 & 45 \\
\hline \multirow{3}{*}{$\begin{array}{l}\text { STRUCTURE } \\
\text { Greater Q } \\
\text { value }\end{array}$} & $K=2$ & $73 / 0$ & $37 / 0$ & $22 / 20$ & $0 / 35$ & $5 / 46$ & $1 / 22$ & $0 / 23$ & 284 & \\
\hline & $K=3$ & $73 / 0 / 0$ & $25 / 12 / 0$ & $1 / 41 / 0$ & $0 / 10 / 25$ & $3 / 0 / 48$ & $0 / 1 / 22$ & $0 / 23 / 0$ & 284 & \\
\hline & $K=5$ & $73 / 0 / 0 / 0 / 0$ & $1 / 36 / 0 / 0 / 0$ & $0 / 0 / 42 / 0 / 0$ & $0 / 15 / 6 / 12 / 2$ & $0 / 0 / 0 / 51 / 0$ & $0 / 0 / 0 / 1 / 22$ & $0 / 0 / 0 / 0 / 23$ & 284 & \\
\hline
\end{tabular}

DAPC

\begin{tabular}{llllllll} 
DAPC $=2$ & $28 / 45$ & $19 / 18$ & $32 / 10$ & $29 / 6$ & $41 / 10$ & $13 / 10$ & $8 / 15$ \\
\hline DAPC= 3 & $0 / 5 / 68$ & $1 / 20 / 16$ & $0 / 36 / 6$ & $15 / 20 / 0$ & $47 / 2 / 2$ & $22 / 1 / 0$ & $3 / 19 / 1$ \\
\hline DAPC =5 & $1 / 1 / 67 / 4 / 0$ & $0 / 37 / 0 / 0$ & $40 / 1 / 0 / 1 / 0$ & $1 / 2 / 0 / 23 / 9$ & $0 / 5 / 0 / 7 / 39$ & $0 / 1 / 0 / 1 / 21$ & $4 / 2 / 0 / 14 / 3$
\end{tabular}

Table 3. Main polymorphism indicators for each microsatellite 


\begin{tabular}{|lllllll|}
\hline \multirow{2}{*}{ Locus } & \multicolumn{3}{l}{ All accessions (521 genotypes) } & \multicolumn{4}{l|}{ Vitis vinifera (481 genotypes) } \\
\cline { 2 - 7 } & PIC & N & $<1 \%$ & PIC & N & $<1 \%$ \\
\hline MD7 & 0.790 & 17 & 6 & 0.772 & 13 & 4 \\
\hline MD32 & 0.794 & 13 & 5 & 0.796 & 11 & 3 \\
\hline ZAG62 & 0.794 & 15 & 6 & 0.786 & 10 & 2 \\
\hline ZAG79 & 0.841 & 14 & 3 & 0.830 & 12 & 1 \\
\hline EVA2 & 0.854 & 21 & 10 & 0.849 & 17 & 6 \\
\hline ISV2 & 0.842 & 23 & 13 & 0.829 & 18 & 10 \\
\hline WV2 & 0.823 & 17 & 6 & 0.819 & 15 & 4 \\
\hline MD5 & 0.844 & 16 & 7 & 0.839 & 10 & 1 \\
\hline MD27 & 0.811 & 15 & 7 & 0.806 & 10 & 2 \\
\hline MD25 & 0.734 & 14 & 9 & 0.730 & 12 & 7 \\
\hline MD28 & 0.865 & 22 & 11 & 0.858 & 18 & 7 \\
\hline ISV4 & 0.786 & 13 & 6 & 0.780 & 12 & 5 \\
\hline ISV3 & 0.626 & 13 & 7 & 0.623 & 10 & 4 \\
\hline
\end{tabular}

PIC: Polymorphic Index Content; N: number of different alleles; <1\%: number of rare alleles with frequency less than $1 \%$

Table 4. Diversity indices calculated for different sets of genotypes from data of 13 nuclear microsatellite loci.

\begin{tabular}{|c|c|c|c|c|c|c|c|c|c|}
\hline Sample & & $\mathbf{N}$ & $\mathrm{Na}$ & $\mathrm{Ne}$ & Ho & $\mathrm{He}$ & $\mathbf{F}$ & $\mathrm{PI}$ & \multirow{3}{*}{$\begin{array}{l}\text { sP: subpopulation, sP1: } \\
\text { mostly central and southerr }\end{array}$} \\
\hline \multirow[t]{5}{*}{ Most represented countries } & Spain & 82 & 9.15 & 5.08 & 0.829 & 0.790 & -0.053 & $6.02 \mathrm{E}-16$ & \\
\hline & Portugal & 98 & 9.38 & 5.52 & 0.852 & 0.809 & -0.054 & $8.10 \mathrm{E}^{-17}$ & \\
\hline & Italy & 57 & 8.31 & 5.02 & 0.835 & 0.785 & -0.065 & $1.27 \mathrm{E}^{-15}$ & varieties belonging to prole \\
\hline & France & 113 & 9.08 & 4.80 & 0.855 & 0.779 & -0.102 & $2.37 \mathrm{E}^{-15}$ & varieties belonging to prole \\
\hline & Total & 350 & 11.31 & 5.64 & 0.845 & 0.813 & -0.042 & $5.38 \mathrm{E}^{-17}$ & $\begin{array}{l}\text { orientalis, sP4: mostly } \\
\text { Northem Italy and French }\end{array}$ \\
\hline \multirow[t]{7}{*}{ Inferred by STRUCTURE according to $Q \geq 0.78$} & $\mathrm{sP1}$ & 73 & 6.92 & 3.97 & 0.828 & 0.728 & -0.143 & $2.13 \mathrm{E}^{-13}$ & varieties, sP5: mostly \\
\hline & $\mathrm{sP2}$ & 37 & 7.85 & 4.65 & 0.834 & 0.770 & -0.085 & $5.03 \mathrm{E}^{-15}$ & $\begin{array}{l}\text { French and Portuguese } \\
\text { varieties, sP6: mostly }\end{array}$ \\
\hline & sP3 & 42 & 7.08 & 3.95 & 0.799 & 0.730 & -0.101 & $1.72 \mathrm{E}^{-13}$ & \multirow{2}{*}{$\begin{array}{l}\text { French and German } \\
\text { varieties. }\end{array}$} \\
\hline & $\mathrm{sP} 4$ & 35 & 7.77 & 4.51 & 0.829 & 0.765 & -0.087 & $9.78 \mathrm{E}^{-15}$ & \\
\hline & sP5 & 51 & 7.38 & 4.35 & 0.849 & 0.754 & -0.126 & $2.40 \mathrm{E}^{-14}$ & $\begin{array}{l}\text { Q: membership coefficient, } \\
\mathrm{N} \text { : number of accessions, }\end{array}$ \\
\hline & sP6 & 21 & 4.77 & 3.45 & 0.817 & 0.695 & -0.176 & $6.21 \mathrm{E}^{-12}$ & Na: mean number of alleles \\
\hline & Total & 258 & 11.08 & 5.76 & 0.828 & 0.816 & -0.019 & $3.61 \mathrm{E}^{-17}$ & number of alleles per locus, \\
\hline \multirow[t]{7}{*}{ Inferred by STRUCTURE according to the highest Q } & sP1 & 110 & 9.08 & 4.43 & 0.841 & 0.754 & -0.119 & $1.84 \mathrm{E}^{-14}$ & $\begin{array}{l}\text { Ho: observed } \\
\text { heterozygosity, He: }\end{array}$ \\
\hline & $\mathrm{sP2}$ & 90 & 9.62 & 5.14 & 0.839 & 0.795 & -0.058 & $4.54 \mathrm{E}^{-16}$ & expected heterozygosity, F: \\
\hline & sP3 & 70 & 8.62 & 4.52 & 0.825 & 0.764 & -0.086 & $8.20 \mathrm{E}^{-15}$ & $\begin{array}{l}\text { fixation index, PI: } \\
\text { cumulative probability of }\end{array}$ \\
\hline & $\mathrm{sP} 4$ & 78 & 8.85 & 4.90 & 0.825 & 0.785 & -0.055 & $1.13 \mathrm{E}^{-15}$ & identity. \\
\hline & sP5 & 85 & 9.23 & 4.77 & 0.851 & 0.775 & -0.098 & $3.01 \mathrm{E}^{-15}$ & \multirow{2}{*}{$\begin{array}{l}\text { * Four genotypes from sP7 } \\
\text { are included (see } \\
\text { STRUCTURE analysis) }\end{array}$} \\
\hline & sP6 & 44 & 7.23 & 4.21 & 0.818 & 0.743 & -0.102 & $6.75 \mathrm{E}^{-14}$ & \\
\hline & Total & 477 & 12.62 & 5.78 & 0.835 & 0.817 & -0.025 & $3.01 \mathrm{E}^{-17}$ & \multirow{2}{*}{$\begin{array}{l}\text { Table 5. Contribution to } \\
\text { core collections of each } \\
\text { group inferred by } \\
\text { STRUCTURE }(k=7) \text { as }\end{array}$} \\
\hline \multicolumn{2}{|l|}{ All Vitis vinifera* } & 481 & 12.92 & 5.79 & 0.835 & 0.818 & -0.025 & $2.91 \mathrm{E}^{-17}$ & \\
\hline
\end{tabular}

number of accessions 


\begin{tabular}{|c|c|c|c|}
\hline & & \multicolumn{2}{|l|}{ Core collections } \\
\hline & & Core-35 (no rare alleles) & Core-63 (all alleles) \\
\hline \multirow[t]{4}{*}{ sP1 } & $Q \geq 0.78$ & 3 & 6 \\
\hline & admix & 5 & 8 \\
\hline & sP percent & $7.27 \%$ & $12.72 \%$ \\
\hline & Core percent & $22.85 \%$ & $22.22 \%$ \\
\hline \multirow[t]{4}{*}{ sP2 } & $Q \geq 0.78$ & 2 & 6 \\
\hline & admix & 1 & 4 \\
\hline & sP percent & $3.33 \%$ & $11.11 \%$ \\
\hline & Core percent & $8.58 \%$ & $15.87 \%$ \\
\hline \multirow[t]{4}{*}{ sP3 } & $Q \geq 0.78$ & 4 & 5 \\
\hline & admix & 2 & 4 \\
\hline & sP percent & $8.57 \%$ & $12.85 \%$ \\
\hline & Core percent & $17.14 \%$ & $14.29 \%$ \\
\hline \multirow[t]{4}{*}{ sP4 } & $Q \geq 0.78$ & 4 & 6 \\
\hline & admix & 3 & 4 \\
\hline & sP percent & $8.97 \%$ & $12.82 \%$ \\
\hline & Core percent & $20 \%$ & $15.87 \%$ \\
\hline \multirow[t]{4}{*}{ sP5 } & $Q \geq 0.78$ & 4 & 5 \\
\hline & admix & 3 & 8 \\
\hline & sP percent & $8.23 \%$ & $15.29 \%$ \\
\hline & Core percent & $20 \%$ & $20.63 \%$ \\
\hline \multirow[t]{4}{*}{ sP6 } & $Q \geq 0.78$ & - & - \\
\hline & admix & 3 & 4 \\
\hline & sP percent & $6.81 \%$ & $9.09 \%$ \\
\hline & Core percent & $8.58 \%$ & $7.35 \%$ \\
\hline \multirow[t]{4}{*}{ sP7 } & $Q \geq 0.78$ & - & - \\
\hline & admix & 1 & 3 \\
\hline & sP percent & $25 \%$ & $75 \%$ \\
\hline & Core percent & $2.85 \%$ & $4.76 \%$ \\
\hline $\mathrm{He}$ & & 0.825 & 0.833 \\
\hline Ho & & 0.873 & 0.840 \\
\hline
\end{tabular}

sP 1-7: see Table 2.

Ho: observed heterozygosity, He: expected heterozygosity

Figures 

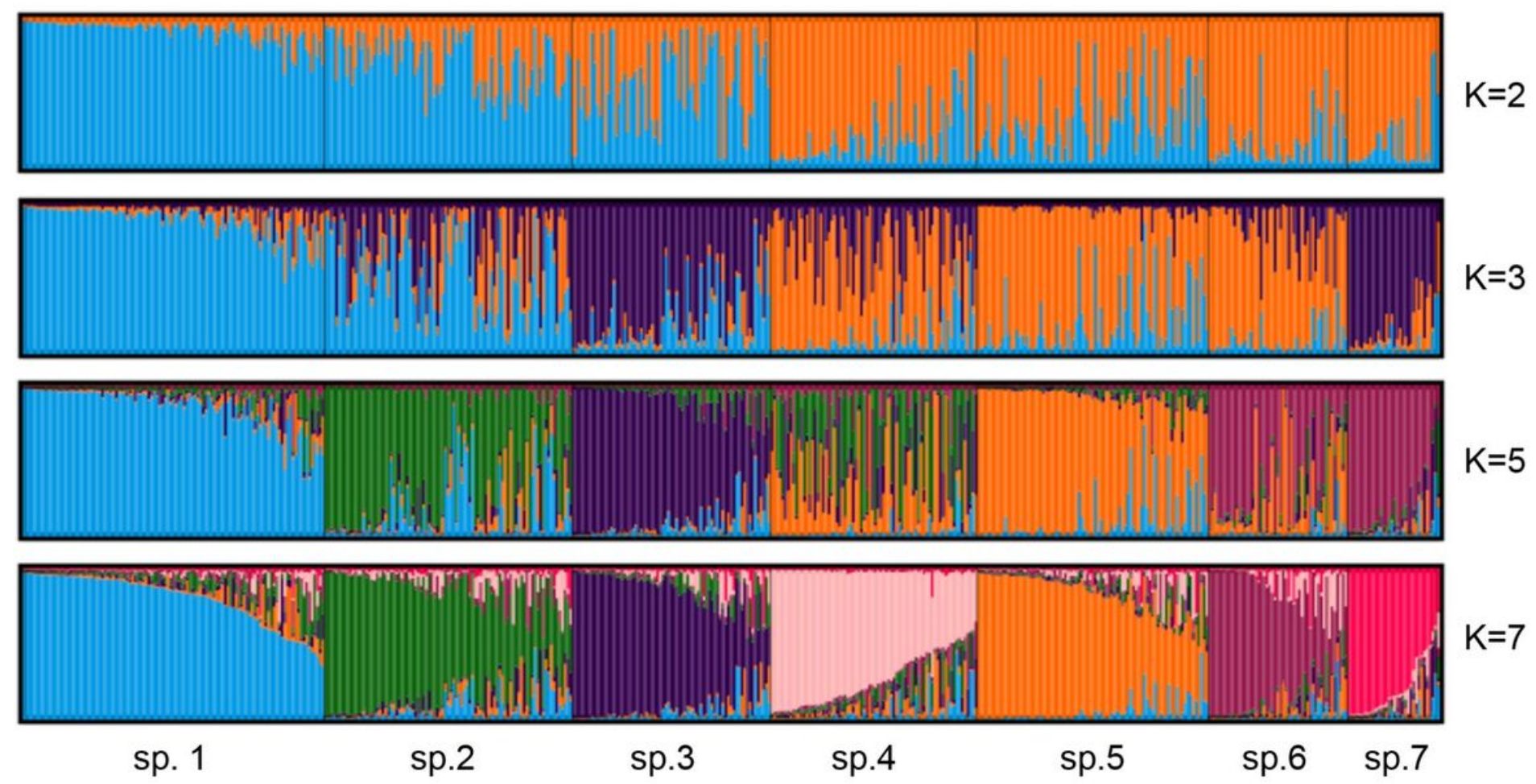

Figure 1

Inferred population structure of the collection using the model-based program STRUCTURE.

Plots generated with the DISTRUCT software based on the Q-matrix consensus permuted across 10 replications for $\mathrm{K}=2$ to $\mathrm{K}=6 \mathrm{using}$ the CLUMPP software. Each accession's genome is represented by a single vertical line, which is partitioned into coloured segments in proportion to the estimated membership in the two, three, five and seven subpopulations 


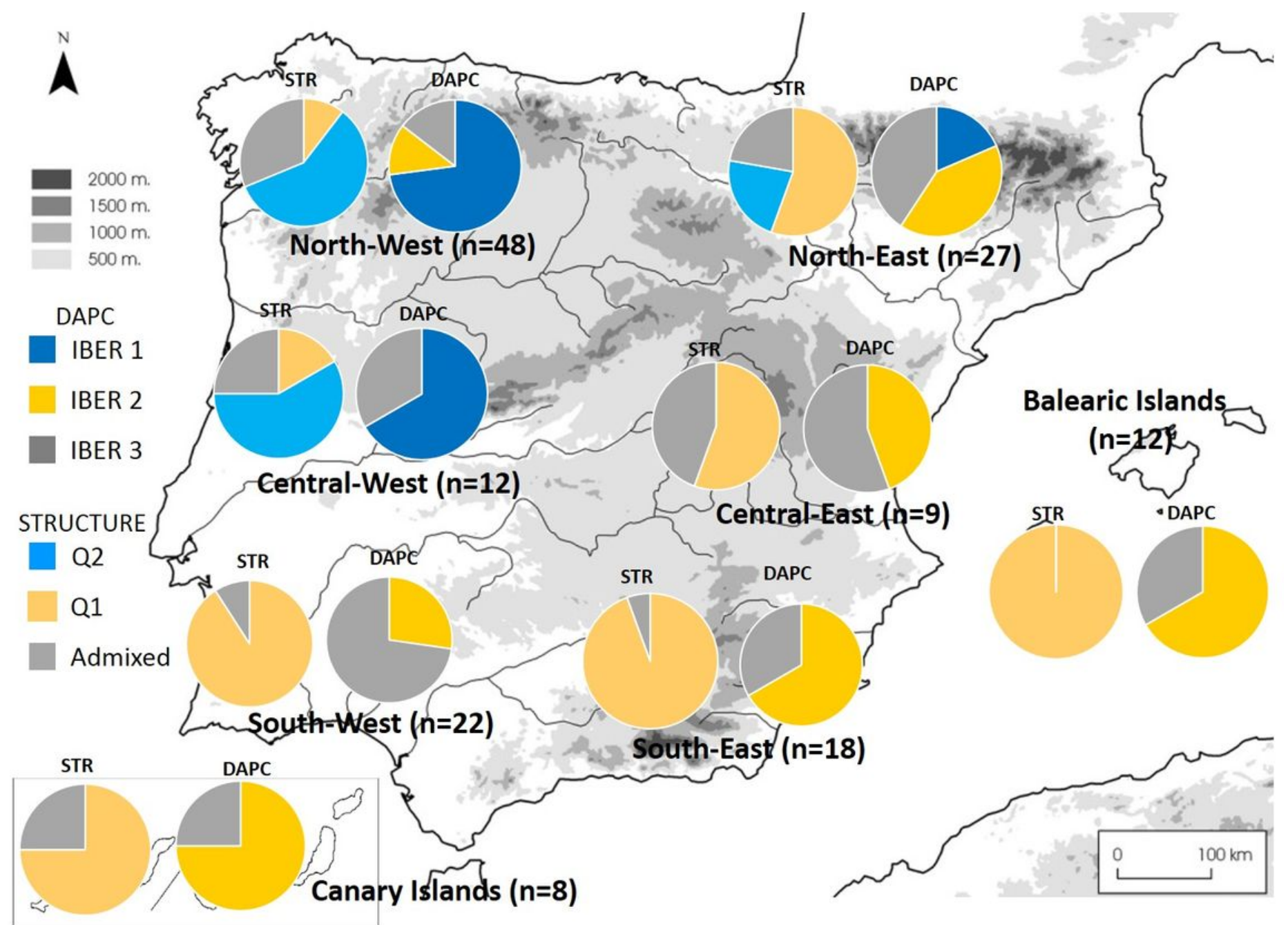

Figure 2

Geographical assignation of Iberian Peninsula genotypes according to STRUCTURE and DAPC analyses.

STRUCTURE analyses best fit at $\mathrm{K}=2$, while DAPC analyses disclose three main subpopulations 


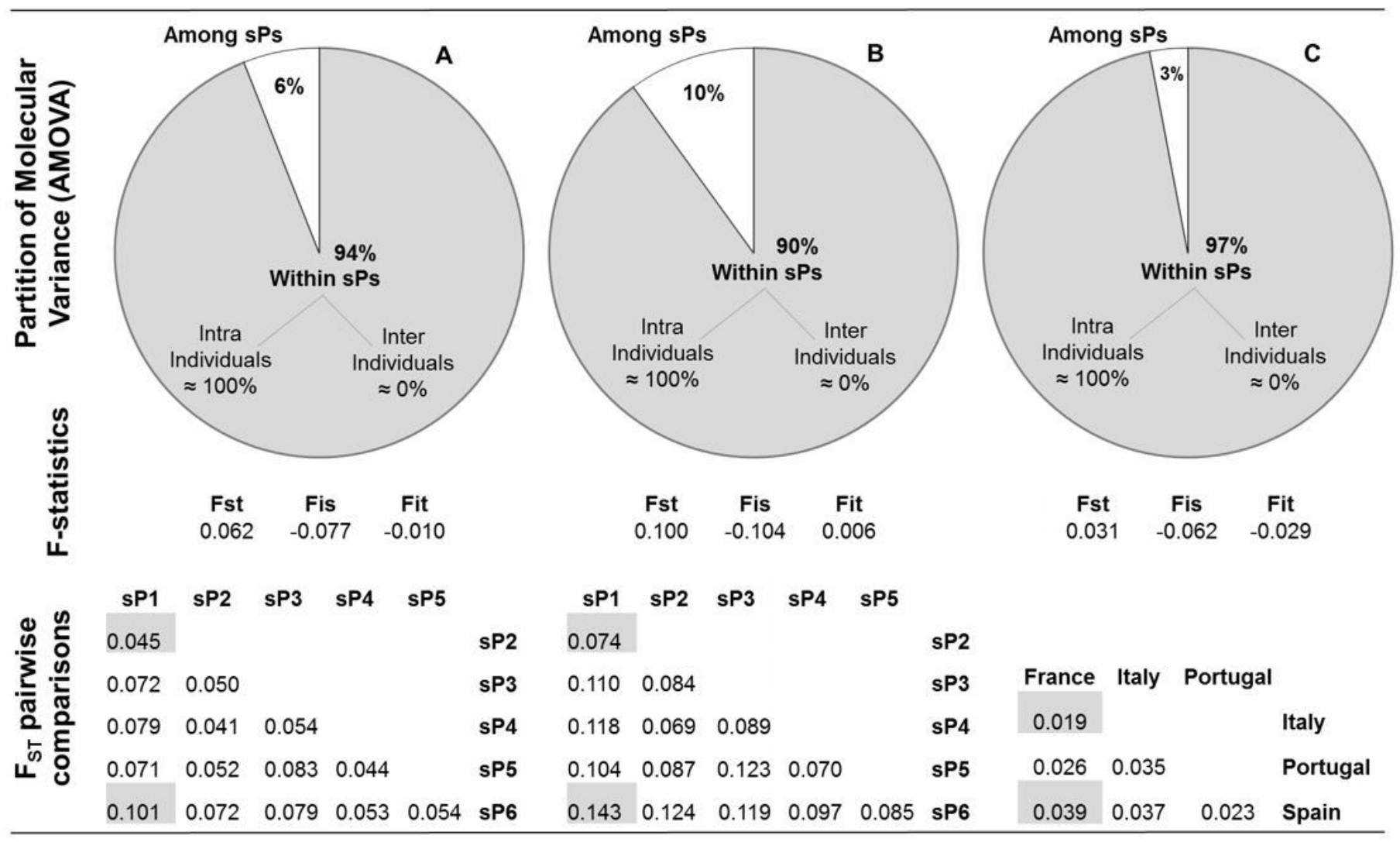

Figure 3

Hierarchical genetic variation and genetic differentiation among and within groups of varieties/accessions.

sP: subpopulation (see table 2).

A): subpopulations inferred by STRUCTURE according to the highest Q (membership coefficient);

B): subpopulations inferred by STRUCTURE according to $Q \geq 0.78$,

C) Most represented countries (variety origin from VIVC).

In order to perform F-statistics via AMOVA, a Codominant-Allelic genetic distance matrix was generated. Absence of population differentiation (FST $\approx 0$ ) was assumed as null hypothesis $(\mathrm{H} 0)$ while FST $>0$ as alternative hypothesis $(\mathrm{H} 1)$, and observed values of FST were compared with 1000 permutated values. All FST values in this figure resulted to be significant $(P \leq 0.001)$

\section{Supplementary Files}

This is a list of supplementary files associated with this preprint. Click to download.
- Additionalfile1.xlsx
- Additionalfile2.pptx
- Additionalfile3.xlsx
- Additionalfile4.pptx
- Additionalfile5.pptx
- Additionalfile6.pptx 